\title{
Chemical Synthesis, Functionalization and Characterization of Multiwalled Carbon Nanotubes
}

\author{
S.S. Gautam ${ }^{1, *}$, G.P. Satsangi ${ }^{1}$, V.R. Satsangi ${ }^{2}$ \\ 1Department of Botany, Dayalbagh Educational Institute Dayalbagh, Agra - 282 005, Uttar Pradesh, India. \\ ${ }^{2}$ Department of Physics and Computer Science, Dayalbagh Educational Institute Dayalbagh, Agra - 282 005, Uttar Pradesh, India.
}

\section{ART I C LEDETAILS}

\section{Article history:}

Received 02 July 2020

Accepted 06 August 2020

Available online 14 September 2020

\section{Keywords:}

Chemical Synthesis

Functionalization

Multiwalled Carbon Nanotubes

\begin{abstract}
A B S T R A C T
This research work is attempted to synthesize, functionalize and to characterize multi walled carbon nanotubes (MWCNTs). The synthesis of multi walled carbon nanotubes was done by chemical vapor deposition (CVD) method. The characterization of MWCNTs was done by adopting the following techniques such as field emission scanning electron microscope, X-ray diffraction, Fourier-transform infrared spectroscopy. The crystalline quality of MWCNTs was confirmed from the analysis of X-ray diffraction pattern. FE-SEM image obtained for MWCNTs and functionalized MWCNTs and it has been seen that dimeter of most of the MWCNTs lies around $90 \mathrm{~nm}$, where as, functionalized MWCNTs diameter is smaller i.e., around $35 \mathrm{~nm}$ only. Fourier-transform infrared spectroscopy study confirmed the presence of $-\mathrm{COOH}$ and $\mathrm{H}$ - bonded $-\mathrm{OH}$ in functionalized MWCNTs.
\end{abstract}

\section{Introduction}

Nanotechnology is the innovation and usage of materials, devices and systems by the control of the properties and structure of the matter at the nano scale. Carbon nano tubes (CNTs) are tubular of Buckminster fullerene was discovered by Iijima [1] in 1991. Carbon nanotubes (CNTs) are nano structured carbon allotropes of cylindrical shape, possessing outstanding physical and chemical properties. They are made up of hexagonal units of carbon. CNTs have superior electrical, mechanical and thermal properties. CNTs are divided as single walled carbon nano tubes (SWCNTs) and multi walled carbon nano tubes (MWCNTs). SWCNTs formed by a single graphene sheet and MWCNTs are formed by several graphene sheets wrapped around the tube core [2]. Multi-walled carbon nanotubes (MWCNTs) are the most important class of carbon nanomaterials with the highest production volumes and numerous technical applications. This is especially important when functionalization is required i.e., grafting of chemical functions at the surface of the nanotubes to add new properties to the CNTs.

\section{Experimental Methods}

\subsection{Synthesis of MWCNTS}

The chemical vapor deposition (CVD) method, mentioned in Fig. 1, involves catalyst assisted thermal decomposition of hydrocarbons, is the most popular method of producing CNTs which is a low cost and scalable technique for mass production of carbon nanotubes $[3,4]$. Carbon source came from an organic compound i.e. toluene mixed with metal catalyst ferrocene and typical carrier gas was taken as argon likely reported by Vivekchand et al. [5].

\subsection{Functionalization of MWCNTS}

MWCNTs were treated by a mixture of nitric and sulfuric acid with a molar ratio of 1:3, respectively. $1 \mathrm{~g}$ of MWCNTs was added to $40 \mathrm{~mL}$ of the acid mixture. Then the oxidation reaction was carried out in a two-necked, round-bottomed glass flask equipped with reflux condenser and stirred by magnetic stirrer. The reaction was continued for 3 hours at $140{ }^{\circ} \mathrm{C}$. Then this mixture was washed with distilled water until the $\mathrm{pH}$ of the filtrate was reached at 7 (neutral), and was dried in a vacuum oven at $70^{\circ} \mathrm{C}$ for 24 hours [6].

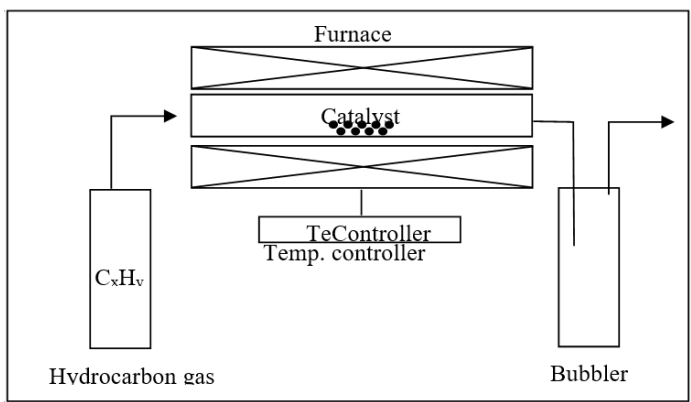

Fig. 1 Schematic diagram of a CVD setup in its simplest form [7]

\subsection{Characterization of MWCNTs and Functionalized MWCNTs}

Characterization of MWCNTs was made by adopting four given techniques and the results were observed which is presented here viz. Xray diffraction, field emission scanning electron microscope and Fouriertransform infrared spectroscopy.

\subsubsection{X-Ray Diffraction}

XRD analysis was studied using BrukerAXSD8 Advance, Germany with $\mathrm{CuK} \alpha$ radiation source wavelength $1.54 \AA$. $2 \theta$ scan range of the samples was $10^{\circ}-80^{\circ}$ with scan speed of 2 seconds/step. This study has been done in Department of Chemistry, Dayalbagh Educational Institute, Agra. X-Ray Diffraction pattern can be explained by following Bragg's equation, $\operatorname{Sin} \theta=$ $\lambda / 2 \mathrm{~d}_{\mathrm{hkl}}$, where, $\theta$ is half of the angle of diffraction beam and incoming beam, $\lambda$ is wavelength of X-ray, and $d_{h k l}$ the interplanar spacing between the planes.

\subsubsection{Field Emission Scanning Electron Microscope}

Surface morphology of MWCNT was investigated by field emission scanning electron microscope (FESEM) using MIRA II LMH from TESCAN. This characterization was done at Inter University Accelerator Centre, New Delhi.

\subsubsection{Fourier-Transform Infrared Spectroscopy}

Structural investigation and functional group were studied by Fouriertransform infrared spectroscopy (FTIR) using Niclot6700 using $\mathrm{KBr}$ as a background. This study is done in Heterogeneous Catalysis and Reaction Engineering Laboratory, Department of Chemical Engineering, IIT Delhi. The resulted spectra were found in a range of $650-4000 \mathrm{~cm}^{-1}$. 


\section{Results and Discussion}

\subsection{Synthesis of Multiwalled Carbon Nanotubes}

For synthesis of MWCNTs, ferrocene was used as catalyst and toluene as carbon source. 3.2 gram of ferrocene was dissolved in $40 \mathrm{~mL}$ of toluene using sonicator. This mixture of toluene and ferrocene was continuously flown in reactor at the rate of $10 \mathrm{~mL} /$ hour along with inert gas (Ar) for 4 hours. Reactor temperature was maintained at $600{ }^{\circ} \mathrm{C}$ for production of MWCNTs by thermal decomposition of hydrocarbon. By following this process about $3 \mathrm{~g}$ of multi walled carbon nanotubes were obtained in one lot. Final removal of the catalysts from the tips of the nanotubes and further purification was done for optimization to yield CNTs of a higher quality $[8,9]$.

\subsection{Functionalization of Multiwalled Carbon Nanotubes}

Functionalization of MWCNTs was done with nitric acid and sulfuric acid with a molar ratio of 1:3. MWCNTs were treated with acid mixture and found that $-\mathrm{COOH}$ and $\mathrm{H}$-bonded $\mathrm{OH}$ functional groups attached with the surface structure of functionalized MWCNTs. This observation was confirmed by Fourier-transform infrared spectroscopy (FTIR).

\subsection{Characterization of Multiwalled Carbon Nanotubes}

\subsubsection{X-Ray Diffraction (XRD)}

The crystalline quality of MWCNTs was confirmed from the analysis of $\mathrm{X}$-ray diffraction pattern (XRD) which is presented in Fig. 2. MWCNTs shows highly crystalline structure with 8 characteristic high intensity peaks at $2 \theta=26.5^{\circ}, 36.0^{\circ}, 38.9^{\circ}, 42.7^{\circ}, 48.7^{\circ}, 57.5^{\circ}, 60.9^{\circ}$ and $65.1^{\circ}$ corresponding to the (002), (020), (111), (100), (110), (101), (004) and (220) planes of hexagonal system respectively. Functionalized MWCNTs showed only one low intensity peak at $2 \theta=26.5^{\circ}$ indicating smaller crystallinity. Similar results were also obtained by many researchers [10$16]$.

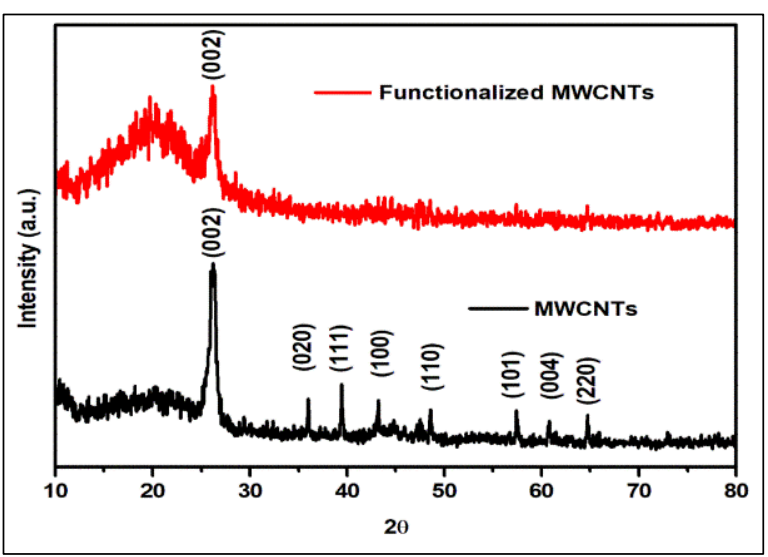

Fig. 2 X-ray diffraction pattern of MWCNT and functionalized MWCNT

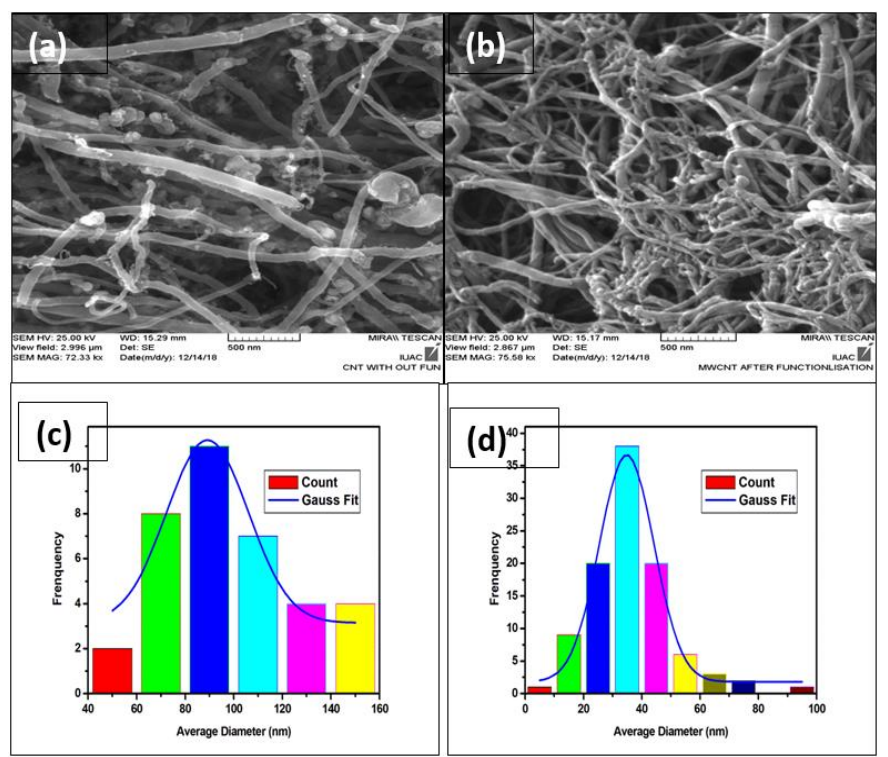

Fig. 3 FE-SEM image of (a) MWCNT, (b) functionalized MWCNT at $500 \mathrm{~nm}$ scale; and Gaussian fitting curve of diameter distribution of (c) MWCNT and (d) functionalized MWCNT

https://doi.org/10.30799/jnst.307.20060302

\subsubsection{Field Emission Scanning Electron Microscope (FE-SEM)}

Under FE-SEM study (Fig. 3), the average diameter size of MWCNTs and functionalized MWCNTs was found $89 \mathrm{~nm}$ and $34 \mathrm{~nm}$ respectively. The average diameter size of functionalized MWCNTs is less than that of the MWCNTs. The reduction in size is caused due to oxidation of MWCNTs with acid mixture $\left(1 \mathrm{HNO}_{3}: 3 \mathrm{H}_{2} \mathrm{SO}_{4}\right)$.

\subsubsection{Fourier-Transform Infrared Spectroscopy (FTIR)}

The FTIR spectral study Fig. 4 shows the presence of different functional groups on the surface of multiwalled carbon nanotubes with the corresponding peaks at $1220 \mathrm{~cm}^{-1}, 1360 \mathrm{~cm}^{-1}$ and $1715 \mathrm{~cm}^{-1}$. After the functionalization of MWCNTs with acid mixture $\left(\mathrm{H}_{2} \mathrm{SO}_{4}\right.$ and $\left.\mathrm{HNO}_{3}\right)$, the peaks were appeared at $1501 \mathrm{~cm}^{-1}[-\mathrm{C}-\mathrm{O}-\mathrm{H}(-\mathrm{O}-\mathrm{C})], 1867 \mathrm{~cm}^{-1}(-\mathrm{C}=0$ medstretching) 2634-3034 $\mathrm{cm}^{-1}$ range (-OH acidic) and $3717 \mathrm{~cm}^{-1}(-\mathrm{O}-\mathrm{H} ; \mathrm{H}-$ bonded). Thus, present study confirmed the existence of $-\mathrm{COOH}$ and $\mathrm{H}$ bonded $\mathrm{OH}$ functional groups in the structure of functionalized MWCNTs. [17-20].

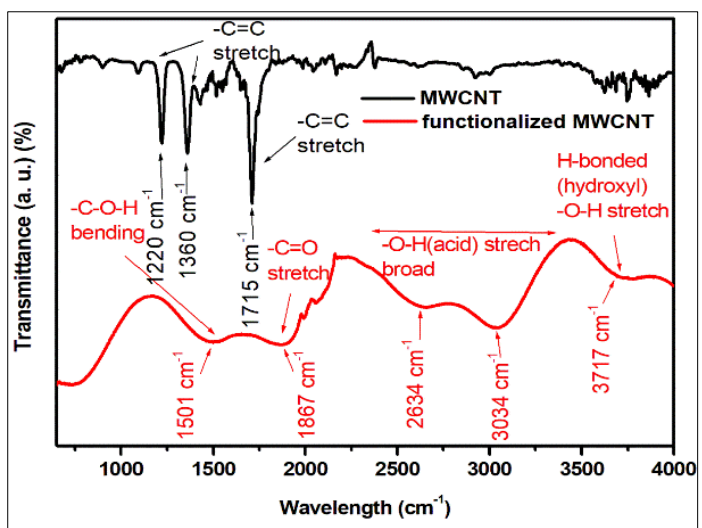

Fig. 4 FTIR spectrum of MWCNT and functionalized MWCNT

\section{Conclusion}

Many factors have been taken into the consideration to synthesize good quality and better quantity of MWCNTs. In the present study the desired quality MWCNTs were resulted from toluene at the flow rate of $10 \mathrm{~mL} / \mathrm{hr}$. These parameters were controlled by simple set-ups which can be manufactured in a common laboratory. X-ray diffraction (XRD) was confirmed the crystalline quality of MWCNTs. Field emission scanning electron microscope (FE-SEM) confirmed the formation of MWCNTs. Average diameter size of MWCNTs and functionalized MWCNTs was found $90 \mathrm{~nm}$ and $35 \mathrm{~nm}$ respectively. Fourier-transform infrared spectroscopy (FTIR) confirmed the functionalization of MWCNTs with - $\mathrm{COOH}$ and $-\mathrm{OH}$ functional group.

\section{Acknowledgement}

Authors are highly grateful to Prof. P.K. Kalra, Director, Dayalbagh Educational Institute, for his encouragement. Prof. J.N. Srivastava, Head, Department of Botany for providing necessary facilities to this study. Dr. Bhanu Pratap, Sr. Scientist, Carbon department, NPL, New Delhi is highly acknowledged for synthesis and characterization of MWCNTs in his Lab. Authors also acknowledge Mr. Neeraj Kumar Biswas, Research Scholar, Dept. of Chemistry D.E.I. Dayalbagh, Agra for help in characterization.

\section{References}

[1] S. Iijima, Helical microtubules of graphitic carbon, Nature 354 (1991) 56-58.

[2] S.B. Sinnott, Chemical functionalization of carbon nanotubes, Jour. Nanosci. Nanotechnol. 2 (2002) 113-123.

[3] A.M. Cassel, J.A. Raymarkers, J. Kong, H. Dai, Large scale CVD synthesis of singlewalled carbon nanotubes, J. Phys. Chem. B. 103(31) (1999) 6484-6492.

[4] E. Couteau, K. Hernadi, J.W. Seo, L.T. Nga, C. Miko, R. Gaal, L. Forro, CVD synthesis of high-purity multiwalled carbon nanotubes using $\mathrm{CaCO}_{3}$ catalyst support for large scale production, Chem. Phys. Lett. 378(1-2) (2003) 9-17.

[5] S.R.C. Vivekchand. M. Celel, F.L. Deepak, A.R. Raju, A. Govindaraj, Carbon nanotubes by nebulized spray pyrolysis, Chem. Phys. Lett. 386 (2004) 313318.

[6] C.E. Hong, J. H. Lee, P. Kalappa, S.G. Advani, Effects of oxidative conditions on properties of multi-walled carbon nanotubes in polymer nanocomposites, Comp. Sci. Tech. 67(6) (2007) 1027-1034. 
[7] K. Varshney, Carbon nanotubes: A review on synthesis, properties and applications, Int. J. Eng. Res. Gen. Sci. 2(4) (2014) 660-677.

[8] M. Morsy, M. Helal, M. El-Okr, M. Ibrahim, Preparation, purification and characterization of high purity multi-wall carbon nanotube, Spectrochim. Acta A 132 (2014) 594-598.

[9] Y. Matsuzawa, Y. Takada, T. Kodaira, H. Kihara, H. Kataura, M. Yoshida, Effective nondestructive purification of single-walled carbon nanotubes based on highspeed centrifugation with a photochemically removable dispersant, J. Phys. Chem. C 118(9) (2014) 5013-5019.

[10] D.S. Kirti, K.N. Roshan, P. Thakur, Preparation, characterization and photocatalytic applications of $\mathrm{TiO}_{2}$-MWCNTs composite, Defence Sci. Jour. 63(4) (2013) 435-441.

[11] E.Y. Malikov, M.B. Muradov, O.H. Akperov, G.M. Eyvazova, R. Puskás, et al., Synthesis and characterization of polyvinyl alcohol based multiwalled carbon nanotube nanocomposites, Physica. 61 (2014) 129-134.

[12] H. He, C. Gao, A general strategy for the preparation of carbon nanotubes and graphene oxide decorated with PdO nanoparticles in water, Molecules 15(7) (2010) 4679-4694.

[13] H. Pal, V. Sharma, R. Kumar, N. Thakur, Facile synthesis and electrical conductivity of carbon nanotube reinforced nanosilver composite, $\mathrm{Z}$. Naturforsch. 67a (2012) 679-684.

[14] K.T. Gupta, S. Kumar, Z.A. Khan, M.K. Varadarajan, J.W. Cantwell, Self-sensing performance of MWCNT-low density polyethylene nanocomposites, Mater. Res. Express 5(1) (2018) 015703:1-7.
[15] M.L. Chen, W.C. Oh, Synthesis and highly visible-induced photocatalytic activity of CNT-CdSe composite for methylene blue solution, Nanoscale Res. Lett. 6(1) (2011) 398:1-8.

[16] S. Zhang, B. Li, Q. Sheng, J. Zheng, Electrochemical sensor for sensitive determination of nitrite based on the CuS-MWCNT nanocomposites, J. Electroanal. Chem. 769 (2016) 118-123.

[17] C. Cunha, S. Panseri, D. Iannazzo, A. Piperno, A. Pistone, M. Fazio, S. Galvagno, Hybrid composites made of multiwalled carbon nanotubes functionalized with $\mathrm{Fe}_{3} \mathrm{O}_{4}$ nanoparticles for tissue engineering applications, Nanotechnol. 23(46) (2012) 465102:1-10

[18] F.A. Azri, R. Sukor, R. Hajian, N.A. Yusof, F.A. Bakar, J. Selamat, Modification strategy of screen-printed carbon electrode with functionalized multi-walled carbon nanotube and chitosan matrix for biosensor development, Asian Jour. Chem. 29(1) (2017) 31-36.

[19] I.O. Armendáriz, E.S. Rodríguez, S.C. Espinoza, D.S.D. Domínguez, I.M. Méndez et al., Evaluation of mechanical and thermophysical properties of chitosan/poly(DL-lactide-co-glycolide)/multiwalled carbon nanotubes for tissue engineering, Am. J. Mater. Sci. 5(1) (2015) 9-16.

[20] A. Nascimento, F.V.A. Dutra, B. C. Pires, K.B. Borges, Efficient removal of antiinflammatory phenylbutazone from an aqueous solution employing a composite material based on poly (aniline-co-pyrrole)/multi-walled carbon nanotubes, New Jour. Chem. 42(9) (2018) 7030-7042. 